\title{
CONVERSAÇÕES SOBRE POVOS INDÍGENAS EM PRÁXIS AUTOBIOGRÁFICAS
}

\begin{abstract}
Resumo: Desde a promulgação dos seus direitos na Constituição de 1988, as assinaturas coletivas dos povos indígenas no Brasil são representativas de uma série de narrativas identitárias configuradas pelos próprios indígenas para dizerem quem são, onde e como querem viver e como desejam ser vistos e respeitados. Há, no entanto, uma lacuna significativa na abordagem dessas textualidades quando pensadas como práticas (auto)biográficas, produzidas tanto no protagonismo coletivo dos povos em suas lutas políticas, quanto na emergência autoral do sujeito histórico indígena, no campo da crítica etnográfica e literária no Brasil. É na esteira desse cenário que pretendemos apresentar uma discussão sobre os povos indígenas em práxis biográficas e autobiográficas, analisando o que dizem as assinaturas coletivas, presentes nessas narrativas, e como os nomes próprios dos chamados índios no Brasil são construídos e significam em nome do grupo.
\end{abstract}

Rafael Xucuru Kariri ${ }^{1}$

Suzane Lima Costa ${ }^{2}$

Palavras-chave: Povos indígenas no Brasil, autobiografia, autoria.

\begin{abstract}
Since 1988, with Brazilian Constitution, the collective signatures of native peoples in Brazil are representative of a series of identity narratives configured by the themselves to say who they are, where and how they live and way they want to be seen and respected. There is, however, a significant gap in addressing these textualities when thought of as biographical practices (self) produced both collective protagonism of the people in their political struggles, as the authorial emergence of indigenous historical subject in the field of ethnographic and literary criticism in Brazil. In the wake of this scenario that we intend to present a discussion on native peoples in biographical and autobiographical practice, analyzing what they say collective, signatures of these stories, and how the names of so-called Indians in Brazil are built and meant for the group.
\end{abstract}

Keywords: native peoples in Brazil, autobiography, authorship.

1 Carlos Rafael da Silva (Rafael Xucuru Kariri) - Mestre em Ciências Sociais na Universidade Federal da Bahia, com bolsa pelo Conselho Nacional de Desenvolvimento Científico e Tecnológico (CNPq). Membro dos grupos de pesquisa "Instituições Políticas Subnacionais", vinculado ao Centro de Recursos Humanos $(\mathrm{CRH})$, e do "Núcleo de Estudos das Produções Autorais dos Povos Indígenas nas Américas" (NEAI), vinculado ao Instituto de Letras, ambos da Universidade Federal da Bahia. Atua como Analista Técnico de Políticas Sociais na Coordenação Geral de Educação Escolar Indígena do Ministério da Educação. Tem interesse nas áreas de políticas públicas, em especial, política educacional e indigenista; movimento indígena; (auto)biografias de lideranças indígenas. É indígena do povo Xucuru-Kariri. Endereço eletrônico: carlos.rafael@mec.gov.br.

2 Professora Adjunta no Departamento de Letras Vernáculas, Instituto de Letras, Universidade Federal da Bahia, com atuação no Programa de Pós-graduação em Literatura e Cultura (UFBA) e no Mestrado profissionalizante em Letras (PROFLETRAS-UFBA), além de colaborar no Programa de Pós-graduação em Língua e Cultura (UFBA). Tem experiência na interface das áreas de Língua Portuguesa e Literatura, desenvolvendo pesquisas sobre autoria e identidade, corpo e subjetividade em práticas de leitura e escrita, educação indígena, (auto)biografias e políticas linguísticas/literárias entre os povos indígenas. Atualmente coordena o Núcleo de Estudos das Produções Autorais dos Povos Indígenas nas Américas (NEAI — UFBA) e o projeto de pesquisa intitulado "As Cartas dos Povos Indígenas ao Brasil" (CNPQ). Endereço eletrônico: suzanelimacosta@gmail.com, suzane.costa@yahoo.com.br. 
Eu só acredito em gente que sabe conversar de perto, bem de perto (Cacique Afonso Pankararé - Aldeia Brejo do Burgo/Glória - BA)

Suzane Lima Costa: Este ensaio faz parte de uma série de conversações mais ampliadas sobre uma questão ainda muito pouco discutida na etnologia brasileira: seria a prática biográfica ou autobiográfica um caminho para apresentar, com seus nomes próprios, Mario Juruna, Galdino Hã-Hã-Hãe, Zabelé Pataxó, Marcelino Tupinambá, Quitéria Binga, Chicão Xucuru, Babau Tupinambá, Maçal Tupaý, Maninha Xucuru-Kariri, Arissana Pataxó e tantos outros, em suas vidas ordinárias, em seus modos de fazer, de estar, de comer, de amar, de atuar no mundo; seria esse um modo de não exotizar o Outro, mas de pensá-lo, contrariando Deleuze (2006), sem perder de vista o seu rosto? Interrogando de duas outras maneiras, poderíamos questionar: quem é o sujeito singular circunscrito sob a rubrica coletiva 'índio' e sempre perlaborado politicamente como Povo Kuikuro, Povo Guarani, Povo Pataxó, Povo Truká, dentre outros? Como fazer valer, na traduzibilidade da pergunta sobre quem é o Outro, não uma vontade de representação, mas de apresentação da vida ordinária daqueles que não tiveram seus nomes inscritos nos paralaxes da grande história?

Rafael Xucuru-Kariri: Essas questões são muito largas e caras. Penso inclusive que, se olharmos para elas de uma forma ligeira, diríamos, que não, esse silenciamento, essa ausência de discussão por parte dos estudos antropológicos e etnográficos não existe, uma vez que todo processo de subjetivação só se efetiva em práxis coletivas. Por outro lado, lembro da primeira vez que falei de mim como extensão do meu Povo, no curso de Ciências Sociais, na UFBa. Quando disse pela primeira vez que eu era Xucuru-Kariri, em um espaço onde outros modos de apresentação dos indígenas, para além dos desenhos românticos, salvacionistas, exóticos, e até mesmo históricos, criam um certo mal-estar, um incômodo coletivo, por vezes, uma descrença em relação a ideia de quem é ou não indígena no Brasil, vi não a negativa direta da minha fala, mas sim a formulação de novas categorias de análise, que promoveram e promovem outro modo de dizer não em interpelações do tipo: se você é índio então você foi aculturado? Mas você não parece índio, então você é índio descendente? Mas se você é índio, então agora você está civilizado? E, veja bem, estamos falando de estudantes do curso de Ciências Sociais e, em algumas situações, de professores universitários, ou seja, imagina-se 
Pontos de Interrogação, v. 4, n. 2, jul./dez. 2014

Revista do Programa de Pós-Graduação em Crítica Cultural

Universidade do Estado da Bahia (UNEB), Campus II — Alagoinhas — BA

então que eu deixo de ser indígena por conta de uma visão que soa até rasa para o avanço que os estudos antropológicos promoveram e promovem desde a década de 1970, com as perspectivas da etnicidade: por eu não espelhar mais a Carta de Caminha. Dentro do que já venho estudando sobre os modos de pensar/fazer autobiografias, creio que nomear o quem do indígena hoje é fomentar desafios que podem alargar semanticamente a ideia de índio no Brasil, para redimensionarmos os paradigmas formadores do imaginário corrente sobre nossas diferentes identidades, isso porque coloca em evidência lugares que raramente vemos serem pensados como próprios da nossa condição política e cultural: o lugar da autoria e, consequentemente, do protagonismo dos indígenas, estejam eles dentro ou fora das suas aldeias.

Suzane Lima Costa: A depender do lugar e da situação, você deixará de ser XucuruKariri, porque o indígena mestrando, aprovado em primeiro lugar no curso de Ciências Sociais, na UFBA, analista político concursado e atuando no MEC, acaba se tornando um problema complexo demais para as velhas/novas categorias de análise que, mesmo pedindo pela fala e visibilidade do Outro, ainda não estão preparadas para sua escuta. Precisamos criar movimentos/manifestos pela escuta agora, para, ao invés de perguntarmos sobre quem pode falar, questionarmos sobre quem está disposto a ouvir (em um sentido muito lato) o outro. No final, estamos falando não só de campos disciplinares, de pesquisas e pesquisadores não muito dispostos para o quem da pessoa comum, para o quem-qualquer, mas estamos tentando colocar em evidência o caráter paradoxal do binômio coletivo/singularidade quando se fala em Povos Indígenas no Brasil, atentando para o fato de que o protagonismo e a autoria dos grupos étnicos indígenas se constituem também na ambivalência do singular no contínuo do coletivo, como ocorre em qualquer grupo social.

Rafael Xucuru-Kariri: Os movimentos coletivos (de qualquer outro grupo social) agregam valores e fortalecem aqueles que os mantém, porém, quando se trata de povos indígenas, a rubrica coletiva que por um lado potencializa e afirma as ações políticas do grupo, por outro acaba ratificando o lugar dos sem nomes próprios, seja pela condição exótica que nos acompanha, seja pelo imaginário de estagnação e quase-morte, desenhado para todos nós, através das narrativas das grandes histórias, da mídia, da escola e de diversos materiais didáticos ideologizados. É como se não houvesse outro modo de ver/ler os Povos Indígenas senão pela imagem estática e grupal (como se a própria histórica fosse estática). Dizendo de outra maneira a mesma coisa, é como se o indígena que sai da aldeia, que estuda na Universidade, 
Pontos de Interrogação, v. 4, n. 2, jul./dez. 2014

Revista do Programa de Pós-Graduação em Crítica Cultural

Universidade do Estado da Bahia (UNEB), Campus II — Alagoinhas — BA

que passa em concursos públicos, que escreve livros e produz filmes, deixasse de ser indígena.

Suzane Lima Costa: Eu acredito que os trabalhos que hoje desenvolvemos, seja nas escolas indígenas, seja no $\mathrm{NEAI}^{3}$, no Observatório da Educação Escolar Indígena, ${ }^{4}$ na SECADI/MEC ${ }^{5}$ ou fora desses espaços institucionalizados, caminham no sentido de promover modos para escaparmos da referência recorrente do índio-corpo-exótico, para pensarmos tanto o lugar coletivo do corpo-mítico, do corpo-histórico, quando as suas implicações nas singularidades do corpo-ordinário, do corpo-comum. Para mim, quem apresenta e tensiona essas questões são as próprias produções autorais dos povos indígenas, desde os escritos da Eliane Potiguara, do Juvenal Payayá, do Olívio Jekupé, do Daniel Munduruku, às práxis de corpo das lideranças indígenas do MUPOIBA ${ }^{6}$ ou da $\mathrm{APIB}^{7}$, como do Cacique Babau, do Jerry Matalawê ou da Sônia Guajajara.

Rafael Xucuru-kariri: Você falou em autoria como práxis de corpo, eu penso que um dos primeiros exercícios que precisamos mover nesses espaços institucionalizados é definir autoria. Aumentar o alcance desse nome, dessa ação, para mostrar quem somos na construção de nós mesmos. Um outro ponto também é trabalhar no sentido de apresentar o que entendemos como práxis autobiográficas. Veja que desde a promulgação dos nossos direitos na Constituição de 1988, as nossas produções autorais são tidas como práxis políticas usadas para que

3 O Núcleo de Estudos das Produções Autorais dos Povos Indígenas nas Américas/NEAI-UFBA iniciou suas atividades, em 2012, com o objetivo geral de produzir e fazer circular as produções biográficas dos Povos indígenas no Brasil, com vistas à caracterização da emergência autoral do sujeito histórico indígena na formação política/literária do Brasil, tendo como um dos seus principais objetivos a futura publicação da coletânea intitulada As Cartas dos Povos Indígenas ao Brasil (Projeto financiado pelo CNPQ).

4 Vinculado ao Programa Multidisciplinar de Estudos Étnicos e Africanos (Pós-Afro) em parceria com o Programa de Pós-Graduação em Antropologia da UFBA e a Licenciatura Intercultural em Educação Escolar Indígena (LICEEI/UNEB), o programa propõe um núcleo de pesquisa na área da linguagem e educação intercultural indígena, com vistas a estimular a produção acadêmica na área e fornecer subsídios para a educação linguística dos Povos Indígenas no Nordeste), sob a coordenação da professora América Lúcia César (UFBA).

5 Secretaria de Educação Continuada, Alfabetização, Diversidade e Inclusão, do Ministério da Educação do Brasil.

6 O Movimento Unido dos Povos e Organizações Indígenas da Bahia (MUPOIBA) é uma das organizações indígenas, presente no Estado da Bahia, que reuni 22 etnias, dentre elas: Tupinambá, Pataxó, Pataxó Hã-hãhãe, Kiriri, Tuxá, Tumbalalá, Atikum, Pankararé, Kaimbé, Pankarú, Pankararú, Xukuru-Kariri, Kariri-XócoFulni-ô, Funi-ô, Potiguara, Tapuia, Kambiwá, Kapinawá, Xacriabá, Payaya, Kantaruré e Tuxi.

7 A Articulação dos Povos Indígenas do Brasil (APIB) é uma instância nacional de deliberação e articulação política do Movimento Indígena no Brasil. Ver: http://blogapib.blogspot.com.br/ acessado em 20 de agosto de 2014. 
Pontos de Interrogação, v. 4, n. 2, jul./dez. 2014

Revista do Programa de Pós-Graduação em Crítica Cultural

Universidade do Estado da Bahia (UNEB), Campus II — Alagoinhas — BA

cada grupo étnico possa dizer de onde fala, como quer viver e como deseja ser visto e respeitado. O que nos leva a perguntar como a sociedade recebe essas produções e como nos apresentamos quando escrevemos, oralizamos, desenhamos, pintamos, protestamos, lutamos, seja nas Cartas do indígenas ${ }^{8}$, que agora estamos juntando para estudarmos e publicarmos, seja nos vídeos, nas músicas, nos mapas, nas cartografias e, com mais frequência, em sites, facebooks e blogs.

Suzane Lima Costa: Para isso, precisamos fazer circular os modos como vocês estão se autorizando como produtores dos seus próprios discursos e como passam a explicar 'quem são' através da retomada das suas memórias, sem esquecer que há uma série de produções que representam e apresentam os povos indígenas em coletâneas e coletivos organizados por ONGs e/ou antropólogos. Essas práticas, com todas as questões e problemáticas que apresentam, são de extrema importância para a construção de um imaginário sobre quem são os Povos indígenas no Brasil. As coleções Índios na visão dos índios, organizada pela Thydêwá9; Cineastas Indígenas, organizada pelo Projeto Vídeos nas Aldeias ${ }^{10}$, Narradores Indígenas do Rio Negro, produzida pela FOIRN — Federação das Organizações Indígenas do Rio Negro; constituem hoje uma significativa mostra disso. Creio que também estaria nesse fato a nossa vontade de alargarmos a noção de autoria, você não acha?

Rafael Xucuru-kariri: Claro, ainda mais porque nessas obras vemos a memória coletiva e as narrativas míticas como suportes e procedimentos para traduzir a identidade indígena

8 Com o projeto As cartas dos Povos indígenas ao Brasil (projeto financiado pelo CNPQ) objetivamos construir o arquivo das cartas produzidas pelos povos indígenas no Brasil, que hoje circulam com ampla repercussão nas redes sociais e em portais de notícias dentro e fora do país, bem como das cartas que, fora do espaço virtual, foram escritas e encaminhadas ao Governo Federal e às organizações internacionais, desde a promulg ação dos direitos indígenas na Constituição de 1988 até a presente data. Como um dos resultados finais desse trabalho, pretendemos publicar a coletânea intitulada 'Cartas dos Índios ao Brasil', bem como fomentar sua veiculação em estabelecimentos públicos de ensino fundamental e médio.

9 A Thydêwá é uma organização não governamental, formalizada em 2002, que atua principalmente no nordeste brasileiro. Desenvolve projetos de formação de indígenas de várias etnias e nações, por meio de oficinas nas aldeias indígenas, para atuarem como pesquisadores, documentalistas, jornalistas, historiadores, antropólogos, poetas, filósofos e fotógrafos de suas próprias realidades, tendo como um de seus resultados a coletânea Índios na visão dos índios. Para mais informações, consultar o site: http://www.thydewa.org/work/indios-navisao-dos-indios/.

${ }^{10}$ Vídeo nas Aldeias é um projeto na área de produção audiovisual indígena no Brasil, criado em 1986. Desde 2000 o projeto se constituiu como uma organização não governamental. Em associação com o Ministério da Educação distribuiu a coletânea Cineastas Indígenas, fruto de oficinas sobre material audiovisual organizadas pela Ong, composta por cinco vídeos realizados por cineastas dos povos Kuikuro, Panará, Huni Kui, Xavante e Ashaninka. O material foi distribuído gratuitamente para escolas, associações e comunidades indígenas e para escolas não indígenas de ensino médio. 
em suas espacialidades e temporalidades e, consequentemente, como um dos suportes para os exercícios das práticas biográficas.

Suzane Lima Costa: Dessas coleções, a mais familiar para vocês é Índios na visão dos índios, que apresenta os diferentes povos indígenas, situados geopoliticamente na Região Nordeste do Brasil, narrando em cânticos, causos, testemunhos, fotografias e desenhos as histórias das suas comunidades. A ênfase desses trabalhos está nos testemunhos das principais lideranças das aldeias, dos caciques e dos pajés.

Rafael Xucuru-Kariri: Essas produções contam a história de cada Povo, embaralhando suas narrativas de fundação com breves informações sobre a identidade étnica de cada grupo. Até então, estão disponíveis em versão impressa e virtual dezessete obras ${ }^{11}$ que descrevem a vida dos Truká, Tumbalalá, Tupinambá, Kiriri, Pataxó Hã-Hã-Hãe, Kariri-Xocó, Fulni-ô, Pataxó do Prado, Pankararu e Potiguara. Em cada capa, vemos enunciado o título Índios na visão dos índios e como subtítulo o nome do grupo étnico que será apresentado, o mesmo ocorre com as obras intituladas Somos Patrimônio (2011), Cultura viva (2012), Cantando as culturas indígenas (2005) e Memória (2012). Nas contracapas da história do Povo Pataxó-HãHã-Hãe, do Povo Truká e do Povo Tupinambá, vemos em destaque, mudando apenas o nome de cada grupo étnico, a seguinte assertiva: “O Povo da nação (nome do Povo) é o verdadeiro autor deste livro. Os textos, as fotografias, os desenhos e a arte-finalização foram feitos pelos próprios índios" (GERLIC, 2007b, 2003b, 2003c).

Suzane Lima Costa: E quem é o Povo dessa nação? Quem é o indígena que versa sobre si mesmo, que se autodesenha e autofotografa? Você viu que Nhenety Kariri-Xocó (AL), Dora Pankararu (PE), Manuel Monteiro da Luz Pankararu (PE), Fabio Baenã Pataxó Hã-HãHãe (BA), Maya Tupinambá Pataxó Hã-Hã-Hãe (BA), Antonio Cícero da Silva Truká (PE), Gringo e Juracy Tupinambá (BA), Antonio e Dona Lurdes Truká (PE) e Maria Pankararu (PE) são alguns dos nomes próprios que estão presentes no final de cada excerto transcrito, de cada testemunho, de cada história narrada. Também nos agradecimentos, presentes nas contracapas, aparece a nomeação de alguns membros da comunidade que colaboraram com a

\footnotetext{
${ }^{11}$ Disponíveis em: <http://www.thydewa.org/downloads1/>.
} 
criação das obras. ${ }^{12}$ Depois que li as obras, vi que a pergunta sobre quem é o Povo da nação é ainda mais abrangente em significados, quando o eu-singular é rememorado na extensão da história coletiva. Isso porque há um investimento, ainda que muito tímido, na apresentação de alguns dos membros do grupo, a exemplo da narrativa do Nailton Pataxó, na coletânea Índio na Visão do índios: memória:

\begin{abstract}
Meu nome é Nailton Muniz Pataxó, da etnia Tupinambá. Sou um dos caciques daqui da Terra Indígena Caramuru - Catarina Paraguaçu, vivo aqui com o povo PATAXÓ HÃHÃHãE. Meu avô era Tupinambá de Olivença e eu nasci no rancho Queimado, na região do Ourinho, no município de Pau Brasil. Os funcionários do SPI (Serviço de Proteção ao Índio) venderam e arrendaram o nosso território e nós começamos a sofrer muito, tendo que sair de nossas terras. Em 1975, me elegeram como uma das lideranças para trabalhar pelos parentes que estavam dentro da área indígena e também para trazer de volta aqueles que estavam fora. (GERLIC, 2007b, p. 24).
\end{abstract}

Rafael Xucuru-kariri: Mas como o Sr. Nailton se tornou cacique? Qual o nome do seu avô? Quem sofreu com ele durante essa história? E antes de ser cacique, quais as narrativas, imagens, desenhos que construíram seu percurso de vida? Mesmo que, de um modo geral, o formato dessas obras não aposte na biografizaçao para apresentar os nomes próprios nelas registrados, essas perguntas nunca são postas como inferências fundamentais para sabermos sobre quem fala quando o índio fala.

Suzane Lima Costa: Você quer dizer então que isso, de certa forma, faz jus à vontade, também autoral, de quem edita, organiza os textos ou coordena as oficinas de criação, no caso específico dessa coletânea, a do antropólogo Sebastián Gerlic. Ou seja, mesmo considerando que todo processo autoral está relacionado às práxis socioculturais resultantes de ações coletivas, pela própria condição dialógica/ intertextual/ polifônica de qualquer texto, não há como ignorar a necessidade de um estudo crítico sobre a relação existente entre o processo de elaboração desses textos e a obra final entregue ao público.

Rafael Xucuru-Kariri: Isso vale para pensarmos quem são os indígenas que participaram do processo de elaboração da coletânea, como também vale para pensarmos o idealizador e organizador do material coletado, no sentido da crítica que produz sobre o outro ou da produção de si que faz reverberar e dos modos como articula ações políticas para o grupo.

12 A coletânea Índios na visão dos índios é produzida a partir de oficinas coordenadas pelo antropólogo Sebastián Gerlic e realizadas nas aldeias indígenas no nordeste, com ampla participação dos membros da comunidade, apoio financeiro do Governo do Estado da Bahia e sob a coordenação geral da ONG Água Dourada Organização Multicultural Indígena do Nordeste. 
Suzane Lima Costa: As Lições que América César (2011) apresenta no texto Autoria e autonomia nos colocam no princípio desse discussão, principalmente porque ela define a questão da autoria em a partir de três aspectos:

a) o da consciência, a elucidação na própria práxis, que remete também ao conceito de crítico; b) o da constituição desse sujeito do discurso: quem é esse autor que se explicita na práxis? Como ele se constitui?; e c) o da construção específica da autonomia nos movimentos minoritários como projeto político (2011, p. 93).

Esses aspectos nos coloca diante de um modo de pensar a autoria como constituinte do corpo de quem fala/faz, como o princípio da ação construída também pela mediação, pelo testemunho ou pela (auto)biografização e que não estão subordinadas meramente ao texto escrito. Por essa perspectiva, poderíamos dizer que é possível haver produções escritas sem que haja autoria (CESAR, 2011, p. 89), da mesma forma que, podemos dizer que a categoria autor, nomeada por Gerlic, quando apresenta os Índios na visão dos índios, diz muito mais da relação entre o autor-criador do que do autor-pessoa. ${ }^{13} \mathrm{O}$ que nos interessa é a simbiose desses lugares autorias, seja como parte constituinte da historialidade ${ }^{14}$ de Nailton Pataxó, seja nos entremeios das narrativas coletivas, nas frestas, quase imperceptíveis, da oralidade, da performance de cada indígena dentro/fora da sua aldeia.

Rafael Xucuru-Kariri: São esses lugares autorais, presente no corpo de fala de Sr. Nailton e de tantos outros narradores das suas próprias vidas, que precisamos investigar, analisando o que dizem as assinaturas coletivas, presentes nessas produções, e como os nomes próprios são construídos e significam em nome do grupo. O Oscar Sáez (2006), no texto $A u$ tobiografia e sujeito histórico indígena, provocou uma discussão particular sobre o porquê da ausência do gênero autobiografia escrita por ou sobre indígenas na bibliografia brasileira, enquanto a bibliografia norte americana e mexicana sobre o mesmo tema é tão extensa e profícua. Os nossos estudos sobre autoria indígena tem caminhado no sentido desse problema levantado por Sáez para também questionar o que significa essa a ausência de produções autobiográficas na bibliografia brasileira?

${ }^{13}$ Discussão iniciada por V. N. Voloshinov/ M. M. Bakhtin em O discurso na vida e o discurso na arte, publicado em 1921.

${ }^{14}$ Ludwing Biswanger (1972) ao apresentar a noção de historialidade a definia como sendo o modo de dizer a narrativa íntima, descrita pelas pessoas através das palavras da sua subjetividade, posta como presença/ausência do quem eu sou em meio ao quem nós somos na cultura ou na história. 
Suzane Lima Costa: Caminhamos no sentido de questionar se essa ausência significaria dizer que os sujeitos indígenas devem ser pensados sempre no coletivo, como se o 'eu' não tivesse um lugar nas narrativas que autorrepresentam o grupo? Ou como se os discursos indígenas tenderiam a desmentir a ilusão individualista, ao dissolver o 'eu' na identidade coletiva de 'povo Yanomani', 'povo Tuxá', 'povo Kuikuro', 'povo Pataxó’?

Rafael Xucuru Kariri: Mas Sáez, de certa forma, invoca uma problemática que não está presente na nossa conversa. Ele acredita que os próprios índios não fazem relatos sem estar atrelados às narrativas do seus povos. Para Saez:

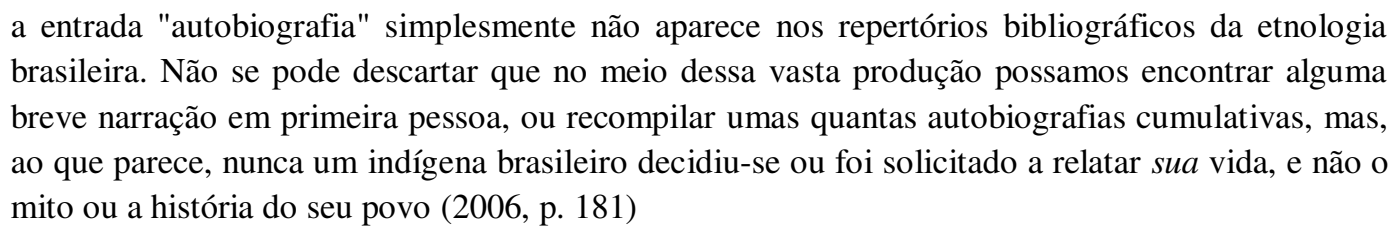

Nesse ponto eu discordo de Sáez. Acredito que sim, o indígena brasileiro decidiu-se a relatar a sua vida. Nossas ações em qualquer perspectiva são parte da nossa biopolítica, da nossa bioficção e elas se apresentam nas vozes das lideranças políticas do movimento indígena, bem como em textos literários, entrevistas, materiais didáticos, cartas, materiais audiovisuais e textos avulsos nas redes sociais, perfazendo uma variedade de formatos e modos utilizados por diversos membros da comunidade para falar de "si". Por outro lado, não discordo totalmente de Sáez, porque concordo com a sua colocação sobre a vida narrada estar tão implicada no mito e na história do povo que as autobiografias dos indígenas estarão sempre espaçadas, sempre em simbiose com o coletivo, impregnadas por cada outro do grupo, como se os indígenas nunca pudessem ser pensados fora da aldeia, do coletivo, da representação de grupo.

Suzane Lima Costa: Não podemos também esquecer que a entrada autobiografia sugerida pelo Sáez está totalmente vinculada a noção de gênero. Acredito que hoje, falar em autobiografias exige que se alargue a noção canônica de gênero, pondo em evidência os modos e os diferentes suportes escolhidos pelos sujeitos para narrativizarem as suas trajetórias de vida. Alargar a noção significa atentar para a multiplicidade de configurações com as quais estamos lidando quando falamos sobre as nas narrativas vivenciais. Nossa questão não é pensar o gênero autobiográfico, mas sim discutir a formação de um espaço de narrativas autorais indígenas, muito próximo ao que Arfuch (2002) chamou de formação de um espaço biográfico mais 
dilatado que o gênero, e que abrange, não a pureza da sua significação, mas sim as interações, as inter-relações, o hibridismo das formas, de seus deslizamentos metonímicos, de sua intertextualidade (2002, p. 114).

Rafael Xucuru-Kariri: Da mesma forma que precisamos também compreender como parte significativa desse espaço biográfico, quando se fala da produção autoral dos povos indígenas, necessita ser mapeada e colocada em circulação, justamente para que possamos mais amplamente discutir os significados dessa ausência, constatada pelo Oscar Sáez, bem como para que essas textualidades possam ser tratadas como práxis política da memória dos indígenas. Quando lembro do Fórum Estadual de Educação Indígena da Bahia e da solicitação de Nádia Tupinambá para que nos formássemos memorialistas das lutas indígenas, sinto que estamos no caminho certo. Lembro que em muitas entrevistas que realizei naquele evento, com foco nas histórias de vidas das lideranças indígenas, quase todos os professores entrevistados me pediam o vídeo, pois queriam usá-lo como material para seus livros e escritos autobiográficos. Ao mesmo tempo as narrativas eram muito complexas, sempre oscilando entre o "eu" e o "nós". Dessa forma, a ideia do autobiográfico que defendemos não parte da construção de narrativas individualizadas e centralizadas num "eu" ensimesmado, mas ativa a função estética e política de criação do si/outro, do si em alteridades.

Suzane Lima Costa: Todavia, se por um lado, as narrativas coletivas valem como práxis políticas para legitimar o si mesmo no grupo, por outro também fazem valer, principalmente no imaginário corrente sobre os indígenas no Brasil, a ideia de um coletivo unificado, essencializado, centralizado, que somente pode colocar em agenciamentos singularidades mitificadas, impessoais, não actantes. Você não acha que talvez o perigo esteja no fato de as assinaturas coletivas, mesmo como uma das estratégias políticas para afirmação do grupo, produzirem uma complexa relativização, como em algumas obras da coletânea Índios na visão dos índios, e acabar, de certa forma, estruturando a cena ordinária da vida de cada um dos membros dos grupos somente com base nos paradigmas tradicionais de descrições etnográficas. Você percebeu isso na leitura que fizemos dos materiais de autoria indígena?

Rafael Xucuru-Kariri: Claro que sim. As imagens mais recorrentes de um corpoordinário, presentes nos pequenos excertos da coletânea Índios na visão dos Indios, são reconfiguradas na coletânea Narradores do Alto Rio Negro, que congrega o falar de "si" e o falar de "nós" em narrativas míticas. No caso dessa coletânea, os Desano, Tukano, Tariano, Bani- 
Pontos de Interrogação, v. 4, n. 2, jul./dez. 2014

Revista do Programa de Pós-Graduação em Crítica Cultural

Universidade do Estado da Bahia (UNEB), Campus II — Alagoinhas — BA

wa, Pira-Tapuia, Arapasso e Tuyuka, localizados geopolicamente no noroeste da Amazônia, são os povos que narram suas mitologias, com especial atenção para as versões dos clãs que compõem esses coletivos. Trata-se de uma produção marcada pela presença de narradores, geralmente anciões, que contam a seus filhos, os seus intérpretes, a história ancestral da comunidade. Com o auxílio de antropólogos, os intérpretes realizam a tradução dos mitos e histórias para o português, revisam os textos e os editam. O trabalho também envolve as atividades de digitação, apresentação, sistematização de notas linguísticas, notas de rodapé, glossários, mapas, design gráfico e ilustração e a edição é viabilizada por duas organizações indígenas, a Federação das Organizações Indígenas do Rio Negro (FOIRN) e a União das Nações Indígenas do Rio Uaupés Acima (Unirva), e uma entidade indigenista, o Instituto Sociambiental (ISA). Até então foram publicados oito volumes numa coletânea denominada Narradores Indígenas do Rio Negro ${ }^{15}$. Sem contar que, o objetivo comum dos livros está na necessidade de evidenciar a autoria indígena. No terceiro volume Pãrõkumu diz que "é a primeira vez que a visão indígena do contato com os brancos é publicada pelos índios" (PÃRÕKUMU; KEHÍRI; RIBEIRO, p. 9).

Suzane Lima Costa: Nessas obras, eu notei não só o desejo dos autores indígenas e indigenistas em evidenciar o protagonismo da autoria aos narradores e intérpretes, mas também a necessidade de se manter viva a memória coletiva por meio do instrumento da escrita. Fiquei pensando na fala de Adriano (Kali), narrador Desana, quando ele diz que o livro foi ditado "para o futuro, para os nossos filhos, para os nossos netos, para as futuras gerações saberem" e para que "aqueles que estão interessados possa aprender. É por isso que este volume foi feito" (UCHILLET; BARBOSA; GARCIA, A.; GARCIA, P. ; GARCIA, B., 2000, p. 10). Há o desejo de se transmitir, por parte dos narradores, a versão das narrativas míticas memo-

$15 \mathrm{O}$ volume 1 enuncia que a vontade de registrar as narrativas fundacionais não vem de agora. “Antes o mundo não existia: mitologia dos antigos Desana-Kêhíripõrã”, é a obra que o Desana Luís Lana e a antropóloga Berta Ribeiro publicaram na década de 1970. O segundo volume reúne a "A Mitologia Sagrada dos Desana-Wari Dihputiro Porã". O volume 3 resultou do trabalho do antropólogo Robin Wright entre as aldeias Baniwa na década de 1970, reunindo orações, canções, histórias e cantos xamânicos de sete diferentes narradores, dos Hohodene e dos Walipere dakenai, dois grupos Baniwa. Desse material resultou o livro "Waferinaipe Ianheike: a sabedoria dos nosso antepassados." Os outros cinco volumes dão continuidade à perspectiva da coleção de evidenciar a autoria indígena: "Upiperi Kalísi: Histórias de antigamente"; "Dahsea Hausirõ Porã ukũshe Wiophesase merã bueri turi: mitologia Sagrada dos Tukano Hausirõ Porã"; "Isã yekisimia Masîke" — O conhecimento de nossos antepassados — Uma narrativa Oyé"; "Livro dos Antigos Desana — Guahari Diputiro Porã" e "Bueri Kãdiri Maririye — Os ensinamentos que não se esquecem". 
radas por seus antepassados. Também há a intenção de se narrar os mitos e histórias não só para seus respectivos clãs, mas também para outros clãs e povos indígenas.

Rafael Xucuru-Kariri: Por isso que na coleção Narradores Indígenas do Rio Negro, diferente da organização da coleção Índios na Visão dos Índios, o que se constrói é uma textualidade voltada exclusivamente para as narrativas míticas, envolvendo a criação do mundo e da humanidade, do fogo, da mandioca, dos artefatos de pesca, das constelações, dos instrumentos musicais, cantos, danças, falas cerimoniais, dos símbolos de guerra, dos contatos com o homem branco. Não há marcadores explícitos que demarquem o lugar do $e u$, constituinte também da condição autoral dos textos. Aparentemente, as histórias fluem de forma autônoma, como se o mito se autonarrasse. Entretanto, os narradores contextualizam os locais ou tempos nos quais as histórias se passam, demarcando um espaço de presença na trama. Em algumas passagens, há o aparecimento do "eu", do "nós", da nomeação do autor, sempre inserido na narrativa mítica ou nos modos de coletivizar as ações e os pertencimentos, em expressões do tipo: "nós", netos de determinado guerreiro mítico, filhos de uma liderança, descendentes de um fundador.

Suzane Lima Costa: Há uma complexidade na composição dessa autoria. Essa simbiose entre "eu" e "nós" não significa a diluição da autoria ao ponto de a perdemos de vista, mas sim uma autoria que se realiza na ambivalência dos efeitos desses dois extremos. Nessas histórias não há um "eu" absoluto, posto que sempre surge mediado, ou mesmo implicado, no "nós" narrativo. Tampouco se pode dizer que a autoria coletiva seja absoluta, pois há um reconhecimento na apresentação das obras de que se trata de uma versão da história de um povo dentre outras versões, mediada em língua portuguesa por um antropólogo. Por vezes, parece que a narrativa é distante do próprio narrador, que simplesmente relata algo passado, aparentemente desconexo à sua história de vida, mas em outras oportunidades o texto é recheado de referências biográficas, pelo fato de o mito ser constituinte do próprio narrador, que relata a sua vida por meio da história de seu clã. É essa ambivalência entre a primeira e a terceira pessoa do singular que sugere não só a ampliação da noção de gênero autobiográfico, da qual falamos, mas também a desmontagem da ideia de um eu indivíduo individualizante.

Rafael Xucuru-Kariri: São esses modos de documentar a memória indígena que precisam ser amplamente difundidos, discutidos e apresentados aos não indígenas, no caminho dos nossos nomes próprios, que coletivizam e singularizam, para além de uma vontade de verdade 
sobre a nossa representação, mas inscrevendo essa existência nas narrativas do mundo. É por isso que esta nossa conversa precisa ser esticada, com muita delicadeza e atenção, para encontrar com os donos e donas dos nomes próprios que colocamos nessa ciranda.

Suzane Lima Costa: Precisamos, como bem nos ensinou o Cacique Afonso, chamá-los para conversar de perto.

Rafael Xucuru-Kariri: Bem de perto.

\section{REFERÊNCIAS:}

ARFUCH, Leonor. El espacio biográfico: dilemas de la subjectividad contemporânea. Buenos Aires: Fondo de Cultura Economica de Argentina, 2002.

BINSWANGER, L. Tres formas de la existencia frustrada. Exaltación, excentricidad, manierismo. Buenos Aires: Amorrortu, 1972.

DELEUZE, G. Diferença e repetição. Trad. R. Machado e L. Orlandi. Rio de Janeiro: Graal, 2006.

SÁEZ, Oscar Calavia. Autobiografia e sujeito histórico indígena: considerações preliminares. Novos Estudos CEBRAP, São Paulo, n. 76, nov. 2006. Disponível em:

$<$ http://www.scielo.br/scielo.php?script=sci_arttext\&pid=S010133002006000300009\&lng=en \&nrm=iso>. Acesso em: 12 maio 2013.

Coleção Índios na visão dos índios:

GERLIC, Sebastián (Org.). Índios na visão dos índios: Arco Digital. Salvador: Thydêwá, 2008a.

Índios na visão dos índios: cantando as culturas indígenas. Salvador: Thydêwá, 2005. Índios na visão dos índios: cultura viva. Salvador: Thydêwá, 2012a. Índios na visão dos índios: Fulni-ô/PE. Salvador: Thydêwá, 2001a. Índios na visão dos índios: Kariri-Xocó/AL. Salvador: Thydêwá, 2001b. Índios na visão dos índios: Kiriri/BA. Salvador: Thydêwá, 2003a. Índios na visão dos índios: memória. Salvador: Thydêwá, 2012b. Índios na visão dos índios: Nós Tupinambá/BA. Salvador: Thydêwá, 2008b. Índios na visão dos índios: Pankararú/PE. Salvador: Thydêwá, 2001c. Índios na visão dos índios: Pataxó do Prado. Salvador: Thydêwá, 2007a. Índios na visão dos índios: Pataxó Hãhãhãe. Salvador: Thydêwá, 2007b. Índios na visão dos índios: Potiguara. Salvador: Thydêwá, 2011a. Índios na visão dos índios: Truká/PE. Salvador: Thydêwá, 2003 b. Índios na visão dos índios: Tumbalalá/BA. Salvador: Thydêwá, 2001d. 
. Índios na visão dos índios: Tupinambá/BA. Salvador: Thydêwá, 2003c. Índios na visão dos índios: somos patrimônio. Salvador: Thydêwá, 2011 b.

Coleção Narradores Indígenas do Rio Negro:

PÃRÕKUMU, Umusi; KEHÍRI, Tõrãmu; RIBEIRO, Berta. Antes o mundo não existia: mitologia dos antigos Desana-Kêhíripõrã. São Gabriel da Cachoeira: UNIRT/FOIRN, 1995. 264 p. (Coleção Narradores Indígenas do Rio Negro, 1).

FERNANDES, Américo Castro (Diakuru); FERNANDES, Dorvalino Moura (Kisibi). A mitologia sagrada dos antigos Desana do grupo Wari Dihputiro Põrã. São Gabriel da Cachoeira: UNIRT/FOIRN, 1996. 196 p. (Coleção Narradores Indígenas do Rio Negro, 2).

WRIGHT, Robin M. (Org.). Waferinaipe Ianheke: A sabedoria dos nossos antepassados histórias dos Hohodene e dos Walipere-Dakenai do rio Aiari: Rio Aiari/São Gabriel da Cachoeira: ACIRA/FOIRN, 1999. 192 p. (Coleção Narradores Indígenas do Rio Negro, 3).

UCHILLET, Dominique (Org.). BARBOSA, Manuel Marcos; GARCIA, Adriano Manuel; GARCIA, Pedro; GARCIA, Benjamin (Narradores). Upíperi Kalísi: histórias de antigamente — histórias dos antigos Taliaseri-Phukurana (versão do clã Kabana-idakena-yanapere). São Gabriel da Cachoeira/Iauareté: FOIRN/UNIRVA, 2000. (Coleção Narradores Indígenas do Rio Negro, 4).

AEZEVEDO, Miguel; AZEVEDO, Antenor Nascimento. Dahsea Hausirõ Porã ukũshe Wiophesase merã bueri turi: mitologia sagrada dos Tukano Hausirõ Porã. São Gabriel da Cachoeira: FOIRN/UNIRT, 2003. 256 p. (Coleção Narradores Indígenas do Rio Negro, 5).

MAIA, Moisés; MAIA, Tiago. Isã yekisimia Masîke"': o conhecimento de nossos antepassados - uma narrativa Oyé. São Gabriel da Cachoeira: FOIRN, 2004. 124 p. (Coleção Narradores Indígenas do Rio Negro, 6).

BUCHILLET, Dominique (Org.). GALVÃO, Wenceslau Sampaio; GALVÃO, Raimundo Castro (Narradores). Livro dos antigos Desana: Guahari Diputiro Porã. São Gabriel da Cachoeira: FOIRN/ONIM, 2004. 687 p. (Coleção Narradores Indígenas do Rio Negro, 7).

BUCHILLET, Dominique (Org.). FERNADES, Américo Castro; FERNADES, Durvalino Moura (Narradores). Bueri Kãdiri Maririye: os ensinamentos que não se esquecem. São Gabriel da Cachoeira: UNIRT/FOIRN, 2006. 167 p. (Coleção Narradores Indígenas do Rio Negro, 8).

Recebido em: 19 de outubro de 2014.

Aceito em: 20 de novembro de 2014. 